\title{
Are patients with obesity "scapegoats"? The obesity prejudice levels of health care workers in Turkey
}

\author{
Hülya Parildar ${ }^{1 *}\left(\mathbb{D}\right.$, Ozge Ucman Tuncer ${ }^{2}$ (D), Mustafa Kursat Sahin ${ }^{3}$ (D), \\ Mustafa Demirpençe ${ }^{4}$ (D) Hamiyet Yilmaz ${ }^{4}$ (1)
}

\section{SUMMARY}

OBJECTIVE: This study assessed obesity prejudice levels, attitudes, and perceptions of health care workers toward individuals with obesity and the relationship between health care workers' perceptions of own and society's weight bias, healthy lifestyle preferences, body mass index, and other factors with obesity prejudice levels.

METHODS: This cross-sectional and descriptive study was conducted with 700 health care workers in Turkey via an online survey addressing characteristics, perceptions, and attitudes toward obesity including an obesity prejudice scale. Categorical variables were expressed as frequencies and percentages. The $\chi^{2}$ test was applied to compare categorical variables. The distribution of the data was evaluated by the Kolmogorov-Smirnov test. Normally distributed data were compared by an independent sample $t$-test, while the Mann-Whitney $U$ and Kruskal-Wallis tests were used for comparing non-normally distributed data.

RESULTS: Participants' mean age was $40.2 \pm 11.3$ years and $67.9 \%$ were women. Notably, $57.9 \%$ worked at tertiary health care centers, $85.9 \%$ were physicians, and $64.8 \%$ were family physicians; $25 \%$ were prejudicial, while $58.1 \%$ tended to have prejudice toward individuals with obesity. Obesity prejudice scores were significantly higher among those who were in close contact with and who stated their preference for patients with obesity.

CONCLUSIONS: Half of the participants tended to have prejudice, and one-fourth were prejudicial toward individuals with obesity. These results highlight the necessity of raising awareness of health care workers to reduce prejudicial attitudes that may negatively impact patients with obesity. Stigmatizing experiences might be detrimental, reducing the quality of life with long-term consequences for emotional and physical health.

KEYWORDS: Obesity. Weight prejudices. Obesity bias. Stigmatization.

\section{INTRODUCTION}

Obesity is a common health problem and individuals impacted by this epidemic have to struggle with concomitant disorders including low self-esteem and depression ${ }^{1}$. Despite improvements in the management of obesity, due to multifactorial etiologies including genetic, environmental, sociocultural, and psychological factors, prevention and treatment should be based on a biopsychosocial and patient-centered approach rather than a biomedical approach ${ }^{2,3}$.
Attitudes of health care workers (HCWs) while counseling and managing the patients with obesity are crucial. Reports show that discriminative and stigmatized behavior decreases quality of life, leads to social isolation, decreases applications to health institutions, and affects individual health and society due to an increase in obesity-related problems $s^{4}$. Previous studies showed that the percentage of HCWs with prejudice toward patients with obesity was higher than estimated ${ }^{4,5}$. Reports show that physicians had negative feelings about patients with obesity and

\footnotetext{
${ }^{1}$ Health Sciences University, Izmir Tepecik Training and Research Hospital, Department of Family Medicine - Izmir, Turkey. ${ }^{2}$ Health Sciences University, Izmir Bozyaka Training and Research Hospital, Department of Family Medicine - Izmir, Turkey. ${ }^{3}$ Ondokuz Mayıs University, Faculty of Medicine, Department of Family Medicine - Samsun, Turkey.

${ }^{4}$ Health Sciences University, Izmir Tepecik Training and Research Hospital, Department of Endocrinology and Metabolism - Izmir, Turkey.

*Corresponding author: hulyaparildar@gmail.com

Conflicts of interest: the authors declare there are no conflicts of interest. Funding: none.

Received on July 26, 2021. Accepted on September 08, 2021.
} 
described them as "irresponsible," "incompatible with the management," or "disobeying." Moreover, they tend to spend less time with such patients and demand more laboratory work ${ }^{4-6}$.

In our country, studies that measure obesity prejudice levels of HCWs are limited and include only primary care physicians' and medical/nursing students' attitudes and discriminative behaviors toward patients with obesity. This study aimed to investigate the perceptions, attitudes, and opinions of HCWs in Turkey toward individuals with obesity and evaluate the relation between the obesity prejudice levels and sociodemographic characteristics, body mass index (BMI), lifestyle preferences, and other factors.

\section{METHODS}

This cross-sectional study was conducted between February and March 2021 via an online questionnaire sent to HCWs working in Turkey.

The sample size was calculated as 385 participants by using the formula, OpenEpi, version 3: $n=\left[\operatorname{DEFF}^{*} N p(1-p)\right] /\left[\left(d^{2} / Z^{2}{ }_{1}\right.\right.$ $\left.{ }_{\alpha / 2}^{*}(\mathrm{~N}-1)+\mathrm{p}^{*}(1-\mathrm{p})\right]$ by accepting the total number of HCWs in Turkey as $(\mathrm{N}) 1.033 .767$, the percentage of obesity prejudice possibility existence $(\mathrm{p})$ as $50 \%$, confidence interval as $95 \%$, and confidence limit (d) as 5\%.

The online questionnaire form was sent to HCWs as a Google form via Whatsapp, Facebook, and email groups. The participants were first informed about the purpose of the study, the duration of the questionnaire, the identity of the researchers, and how the data would be kept. Participants who accepted to enter the study and responded positively to the consent form then completed the questionnaire.

The questionnaire was developed based on the revision of related articles, then tested on $15 \mathrm{HCWs}$, and reorganized for accuracy and clarity ${ }^{4,7}$. The self-administered questionnaire form included 53 questions to be completed in $10 \mathrm{~min}$. The questionnaire consisted of two parts. The first part included questions about participants' sociodemographic characteristics, exercise, healthy eating status, body weight and height, attitudes, and perceptions regarding obesity. The second part included questions from the Obesity Prejudice Scale (GAMS-27).

\section{Obesity prejudice scale}

The scale was developed by Ercan et al. and included 27 items ${ }^{8}$. Twelve items included positive expressions, and 15 items included negative expressions, defined as "absolutely agree", "agree", "doubtful", "disagree" and "absolutely disagree" as fivefold Likert scale. Negative expressions were evaluated by reverse scoring. The highest and lowest scores would be 135 and 27, respectively. A score of 68.00 and below was evaluated as unbiased, between 68.01 and 84.99 points tend to be biased, and above 85 points was evaluated as biased ${ }^{8}$.

\section{Statistical analysis}

Data were evaluated by SPSS 21.0. Continuous variables were presented as mean \pm standard deviation or median and minimum-maximum. Categorical variables were expressed as frequencies and percentages. The chi-square test was applied to compare categorical variables. The distribution of the data was evaluated by the Kolmogorov-Smirnov test. Normally distributed data were compared by an independent sample t-test, while the Mann-Whitney U and Kruskal-Wallis tests were used for comparing non-normally distributed data. BMI of the participants was calculated from the data on SPSS, using the formula (the body weight in kilograms divided by body height in meters squared). The study was approved by Tepecik Research and Training Hospital Ethics Committee (dated January 25, 2021, decision number: 2021/01-57).

\section{RESULTS}

The study included 700 Turkish HCWs. Participants' mean age was $40.2 \pm 11.3$ years, $67.9 \%$ were women, and $66.9 \%$ were married. Notably, $57.9 \%$ of participants were working at tertiary health care centers, $85.9 \%$ were physicians, $64.8 \%$ were family physicians, and $41.6 \%$ worked for less than 10 years. According to calculated BMI values, $15.4 \%$ had obesity, $25 \%$ were prejudicial, and $58.1 \%$ showed prejudice toward individuals with obesity (Table 1). Notably, $29.1 \%$ considered losing weight as "difficult" or "very difficult," $79 \%$ thought that society prefers thin individuals than those with obesity, $83 \%$ had relatives with obesity, $42.3 \%$ experienced obesity in their lifetime, $70.4 \%$ went on a diet previously, and $77.9 \%$ stated difficulty with dieting. In addition, $84.4 \%$ were exercising, $48.4 \%$ had healthy eating habits, and $81.7 \%$ of the participants were in close contact with individuals with obesity. Also, 15.1\% were fond of providing health care to patients with obesity, and $3.4 \%$ preferred to have individuals with obesity to be around; $72.7 \%$ thought that obesity imposes a tremendous economic burden on the health system (Table 2).

Table 1. Categorization of Study Participants' Obesity Prejudice Scale Scores.

\begin{tabular}{l|c}
\hline Obesity Prejudice Scale Scores & $\mathrm{n}(\%)$ \\
\hline Non-prejudicial & $118(16.9)$ \\
\hline Tendency for prejudice & $407(58.1)$ \\
\hline Prejudicial & $175(25.0)$
\end{tabular}


Table 2. Characteristics of the study participants.

\begin{tabular}{|c|c|c|}
\hline Characteristics and perceptions of HCWs & Category & $n(\%)$ \\
\hline \multirow{2}{*}{ Sex } & Male & $225(32.1)$ \\
\hline & Female & $475(67.9)$ \\
\hline \multirow{2}{*}{ Marital status } & Married & $468(66.9)$ \\
\hline & Single & $232(33.1)$ \\
\hline \multirow{3}{*}{ Duration of work } & $<10$ years & $291(41.6)$ \\
\hline & 10-20 years & $156(22.3)$ \\
\hline & $>20$ years & $253(36.1)$ \\
\hline \multirow{3}{*}{ Medical Workplace } & Primary care & $189(27.0)$ \\
\hline & Secondary care & $106(15.1)$ \\
\hline & Tertiary care & $405(57.9)$ \\
\hline \multirow{2}{*}{ Occupation } & Non-physician & $100(14.3)$ \\
\hline & Physician & $600(85.7)$ \\
\hline \multirow{2}{*}{ Medical Specialty of Physicians } & Family physician & $389(64.8)$ \\
\hline & Other than the family physician & $211(35.2)$ \\
\hline \multirow{3}{*}{ BMl } & Normal & $359(51.3)$ \\
\hline & Overweight & $233(33.3)$ \\
\hline & Obesity & $108(15.4)$ \\
\hline \multirow{3}{*}{ Self-assessment of own body weight } & Normal & $353(50.4)$ \\
\hline & Overweight & $287(41.0)$ \\
\hline & Obesity & $60(8.6)$ \\
\hline \multirow{3}{*}{ Having difficulty in losing weight } & Very difficult-Difficult & $204(29.1)$ \\
\hline & Do not know & $320(45.7)$ \\
\hline & Very easy-Easy & $176(25.1)$ \\
\hline \multirow{3}{*}{ Thinking that society prefers thin individuals to fat ones } & Agree & $553(79.0)$ \\
\hline & Doubtful & $88(12.6)$ \\
\hline & Disagree & $59(8.4)$ \\
\hline \multirow{2}{*}{ Presence of relative with obesity } & Yes & $581(83.0)$ \\
\hline & No & $119(17.0)$ \\
\hline \multirow{2}{*}{ Presence of own obesity in a lifetime period } & Yes & $296(42.3)$ \\
\hline & No & $404(57.7)$ \\
\hline \multirow{2}{*}{ Doing exercise } & Yes & $591(84.4)$ \\
\hline & No & $109(15.6)$ \\
\hline \multirow{3}{*}{ Eating habits } & Very healthy & $339(48.4)$ \\
\hline & Healthy & $192(27.4)$ \\
\hline & Unhealthy & $169(24.1)$ \\
\hline \multirow{2}{*}{ Experience of dieting } & Yes & $493(70.4)$ \\
\hline & No & $207(29.6)$ \\
\hline \multirow{2}{*}{ Having difficulty with dieting } & Yes & $384(77.9)$ \\
\hline & No & $109(22.1)$ \\
\hline
\end{tabular}


Table 2. Continuation.

\begin{tabular}{l|c|c} 
Characteristics and perceptions of HCWs & Category & $221(31.6)$ \\
\hline \multirow{2}{*}{ Having prejudice towards individuals with obesity } & Yes & $479(68.4)$ \\
\cline { 2 - 3 } Being in close contact with patients with obesity & No & $572(81.7)$ \\
\hline \multirow{2}{*}{ Preferring individuals with obesity to be around } & Yes & $128(18.3)$ \\
\cline { 2 - 3 } & Yes & $24(3.4)$ \\
\hline \multirow{3}{*}{ Fond of providing health care to patients with obesity } & Doubtful & $183(70.4)$ \\
\cline { 2 - 3 } & No & $106(15.1)$ \\
\hline Thinking that patients with obesity impose a & Yes & $401(57.3)$ \\
\hline tremendous economic burden on the health system & Neutral & $193(27.6)$ \\
\hline
\end{tabular}

According to Obesity Prejudice Scale (GAMS-27), female HCWs $(p=0.006)$, married HCWs $(p=0.008)$, and those who worked more than 20 years $(\mathrm{p}<0.001)$ were found to be prejudicial compared with males, with those unmarried, and with the participants who worked less than 20 years, respectively. The study participants who stated not to have prejudice toward individuals with obesity $(\mathrm{p}<0.001)$, who preferred to have individuals with obesity around $(\mathrm{p}<0.001)$, who stated their interest in providing health care to the patients with obesity ( $\mathrm{p}<0.001)$, and the respondents who did not think patients with obesity cause a great burden to the health system $(\mathrm{p}<0.001)$ had significantly higher scores and were found to be prejudicial. The obesity prejudice scale scores did not differ regarding the study participants' workplace, medical specialty, BMI, attitude about society's preference for thin or fat persons, having a relative with obesity, the experience of obesity, doing exercise, healthy eating, the experience of dieting, or having difficulty in dieting (Table 3).

\section{DISCUSSION}

- Obesity management is complex. Stigmatization, bias levels, and HCWs' attitudes have significant roles on the effectiveness of communication with patients with obesity.

- As HCWs are in the frontline of managing obesity, the awareness of their own weight bias is important in reducing prejudice.

- The present study was carried out with the largest sample of HCWs in Turkey and contributes to valuable data.
Obesity prejudice among HCWs leads to extra social, psychological, and medical problems. Motivational interviewing techniques are needed for improving the adherence to treatment in obesity ${ }^{9}$. It is important to approach in an empathic, supportive, explanatory, realistic, and guiding way in the patient-centered and motivational interviewing model because patients avoid health care services due to negative attitudes, behaviors, and suggestions for losing weight when the patients are not ready, and failure of past treatments ${ }^{5-7}$. Studies have shown that physicians did not prefer to treat patients with obesity and stated that they did not expect the patients to be successful in losing weight due to nonadherence to treatment ${ }^{10}$. In our study, $31.6 \%$ of HCWs were found to have prejudice toward individuals with obesity. Akman et al. reported weight bias among physicians and nurses working at primary care but did not assess by an obesity prejudice scale ${ }^{7}$. A study conducted with nursing students in Turkey reported prejudice scale scores as 75.54 , showing that participants were prone to weight bias, and previous studies with students from health-related departments demonstrated that participants had negative attitudes and prejudice toward individuals with obesity. This suggests that studying in health-related departments may not be enough to eliminate or prevent weight bias. Our study found that obesity prejudice levels increased with the duration of work, and a study in Turkey also found that registered nurses had more negative prejudice scores toward persons with obesity than those of student nurses ${ }^{11}$.

In our study, HCWs with obesity did not consider themselves as having obesity but overweight (6.8 out of $15.4 \%$ ) instead. Moreover, study participants with obesity had higher prejudice scale scores than others, but this was not significant. 
Table 3. Comparison of Obesity Prejudice Scale categories by study participants' characteristics.

\begin{tabular}{|c|c|c|c|c|c|}
\hline \multirow[t]{2}{*}{ Characteristics } & \multirow[t]{2}{*}{ Category } & Non-prejudicial & $\begin{array}{l}\text { Tendency } \\
\text { for having } \\
\text { prejudice } \\
\end{array}$ & Prejudicial & \multirow[t]{2}{*}{$p$} \\
\hline & & $\mathrm{n}(\%)$ & $n(\%)$ & $n(\%)$ & \\
\hline \multirow{2}{*}{ Sex } & Male & $35(15.6)$ & $149(66.2)$ & $41(18.2)$ & \multirow{2}{*}{0.006} \\
\hline & Female & $83(17.5)$ & $258(54.3)$ & $134(28.2)$ & \\
\hline \multirow{2}{*}{ Marital status } & Married & $67(14.3)$ & $271(57.9)$ & $130(27.8)$ & \multirow{2}{*}{0.008} \\
\hline & Single & $51(22.0)$ & $136(58.6)$ & $45(19.4)$ & \\
\hline \multirow{3}{*}{ Duration of work } & $<10$ years & $66(22.7)$ & $172(59.1)$ & $53(18.2)$ & \multirow{3}{*}{$<0.001$} \\
\hline & $10-20$ years & $28(17.9)$ & $84(53.8)$ & $44(28.2)$ & \\
\hline & $>20$ years & $24(9.5)$ & $151(59.7)$ & $78(30.8)$ & \\
\hline \multirow{3}{*}{ Workplace } & Primary care & $28(14.8)$ & $116(61.4)$ & $45(23.8)$ & \multirow{3}{*}{0.189} \\
\hline & Secondary care & $12(11.3)$ & $61(57.5)$ & $33(31.1)$ & \\
\hline & Tertiary care & $78(19.3)$ & $230(56.8)$ & $97(24.0)$ & \\
\hline \multirow{2}{*}{ Occupation } & Non-physician & $20(20.0)$ & $46(46.0)$ & $34(34.0)$ & \multirow{2}{*}{0.024} \\
\hline & Physician & $98(16.3)$ & $361(60.2)$ & $141(23.5)$ & \\
\hline \multirow{2}{*}{$\begin{array}{l}\text { Medical specialty of } \\
\text { physicians }\end{array}$} & Family Physician(FP) & $73(18.8)$ & $231(59.4)$ & $85(21.9)$ & \multirow{2}{*}{0.067} \\
\hline & Other than the FP & $25(11.8)$ & $130(61.6)$ & $56(26.5)$ & \\
\hline \multirow{3}{*}{ BMI } & Normal weight & $69(19.2)$ & $203(56.5)$ & $87(24.2)$ & \multirow{3}{*}{0.082} \\
\hline & Overweight & $33(14.2)$ & $148(63.5)$ & $52(22.3)$ & \\
\hline & Obesity & $16(14.8)$ & $56(51.9)$ & $36(33.3)$ & \\
\hline \multirow{3}{*}{$\begin{array}{l}\text { Self-assessment of own } \\
\text { body weight }\end{array}$} & Overweight & $42(14.6)$ & $172(59.9)$ & $73(25.4)$ & \multirow{3}{*}{0.201} \\
\hline & Normal weight & $65(18.4)$ & $207(58.6)$ & $81(22.9)$ & \\
\hline & Obesity & $11(18.3)$ & $28(46.7)$ & $21(35.0)$ & \\
\hline \multirow{3}{*}{$\begin{array}{l}\text { Having difficulty in losing } \\
\text { weight }\end{array}$} & Very difficult- Difficult & $42(20.6)$ & $108(52.9)$ & $54(26.5)$ & \multirow{3}{*}{0.048} \\
\hline & Do not know & $43(13.4)$ & $189(59.1)$ & $88(27.5)$ & \\
\hline & Very easy-Easy & $33(18.8)$ & $110(62.5)$ & $33(18.8)$ & \\
\hline \multirow{3}{*}{$\begin{array}{l}\text { Thinking that society } \\
\text { prefers thin individuals to } \\
\text { fat ones }\end{array}$} & Neutral & $10(11.4)$ & $53(60.2)$ & $25(28.4)$ & \multirow{3}{*}{0.457} \\
\hline & Agree & $100(18.1)$ & $316(57.1)$ & $137(24.8)$ & \\
\hline & Disagree & $8(13.6)$ & $38(64.4)$ & $13(22.0)$ & \\
\hline \multirow{2}{*}{$\begin{array}{l}\text { Presence of relative with } \\
\text { obesity }\end{array}$} & Yes & $91(15.7)$ & $345(59.4)$ & $145(25.0)$ & \multirow{2}{*}{0.15} \\
\hline & No & $27(22.7)$ & $62(52.1)$ & $30(25.2)$ & \\
\hline \multirow{2}{*}{$\begin{array}{l}\text { Presence of own obesity } \\
\text { in a lifetime period }\end{array}$} & Yes & $48(16.2)$ & $173(58.4)$ & $75(25.3)$ & \multirow{2}{*}{0.925} \\
\hline & No & $70(17.3)$ & $234(57.9)$ & $100(24.8)$ & \\
\hline Doing oxorcico & Yes & $99(16.8)$ & $342(57.9)$ & $150(25.4)$ & 0062 \\
\hline Doing exercise & No & $19(17.4)$ & 65 (59.6) & $25(22.9)$ & 0.803 \\
\hline & Healthy as possible & $52(15.3)$ & $204(60.2)$ & $83(24.5)$ & \\
\hline Eating habits & Healthy & $30(15.6)$ & $115(59.9)$ & $47(24.5)$ & 0.371 \\
\hline & Unhealthy & $36(21.3)$ & $88(52.1)$ & $45(26.6)$ & \\
\hline Evnorience of dinting & Yes & $84(17.0)$ & $284(57.6)$ & $125(25.4)$ & 0905 \\
\hline Еxpentence ol aienting & No & $34(16.4)$ & $123(59.4)$ & $50(24.2)$ & 0.905 \\
\hline
\end{tabular}


Table 3. Continuation.

\begin{tabular}{|c|c|c|c|c|c|}
\hline \multirow[t]{2}{*}{ Characteristics } & \multirow[t]{2}{*}{ Category } & Non-prejudicial & $\begin{array}{l}\text { Tendency } \\
\text { for having } \\
\text { prejudice }\end{array}$ & Prejudicial & \multirow[t]{2}{*}{$p$} \\
\hline & & $\mathrm{n}(\%)$ & $\mathrm{n}(\%)$ & $n(\%)$ & \\
\hline \multirow{2}{*}{$\begin{array}{l}\text { Having difficulty } \\
\text { with dieting }\end{array}$} & Yes & $66(17.2)$ & $216(56.3)$ & $102(26.6)$ & \multirow{2}{*}{0.455} \\
\hline & No & $18(16.5)$ & $68(62.4)$ & $23(21.1)$ & \\
\hline \multirow{2}{*}{$\begin{array}{l}\text { Having prejudice towards } \\
\text { individuals with obesity }\end{array}$} & Yes & $52(23.5)$ & $140(63.3)$ & $29(13.1)$ & \multirow{2}{*}{$<0.001$} \\
\hline & No & $66(13.8)$ & $267(55.7)$ & 146 (30.5) & \\
\hline \multirow{2}{*}{$\begin{array}{l}\text { Being in close contact } \\
\text { with patients with obesity }\end{array}$} & Yes & $90(15.7)$ & $332(58.0)$ & $150(26.2)$ & \multirow{2}{*}{0.121} \\
\hline & No & $28(21.9)$ & 75 (58.6) & 25 (19.5) & \\
\hline \multirow{3}{*}{$\begin{array}{l}\text { Preferring individuals with } \\
\text { obesity to be around }\end{array}$} & Yes & $1(4.2)$ & $10(41.7)$ & $13(54.2)$ & \multirow{3}{*}{$<0.001$} \\
\hline & Doubtful & $67(13.6)$ & $292(59.2)$ & $134(27.2)$ & \\
\hline & No & $50(27.3)$ & $105(57.4)$ & $28(15.3)$ & \\
\hline \multirow{3}{*}{$\begin{array}{l}\text { Fond of providing health } \\
\text { care to patients with obesity }\end{array}$} & Yes & $9(8.5)$ & $53(50)$ & $44(41.5)$ & \multirow{3}{*}{$<0.001$} \\
\hline & Neutral & $53(13.2)$ & $246(61.3)$ & $102(25.4)$ & \\
\hline & No & $56(29)$ & $108(56)$ & $29(15)$ & \\
\hline \multirow{2}{*}{$\begin{array}{l}\text { Thinking that the patients } \\
\text { with obesity impose a } \\
\text { tremendous economic } \\
\text { burden on the health system }\end{array}$} & Yes & $96(18.9)$ & $310(60.9)$ & $103(20.2)$ & \multirow[b]{2}{*}{$<0.001$} \\
\hline & No & $22(11.5)$ & $97(50.8)$ & $72(37.7)$ & \\
\hline
\end{tabular}

Bold values indicate statistical significance.

Due to psychological disturbance, these participants might first stigmatize themselves, which might cause high prejudice levels. Internalized obesity prejudice is the acceptance of these negative attitudes by individuals with obesity, caused by the stigmatization and prejudice demonstrated by other individuals and resulted in low self-esteem, depression, impaired body image, problems related to body weight, and eating disorders $^{12}$. Similar studies showed that high BMI among HCWs was positively related to prejudice levels ${ }^{13}$. Latner et al. conducted a study among overweight individuals and those with obesity and reported that those with internalized obesity prejudice had more physical, psychological, and social problems and lower quality of life $\mathrm{f}^{14}$. Our participants who preferred to have individuals with obesity around and interested in providing health care to patients with obesity had higher prejudice scores. Moreover, HCWs who considered themselves without prejudice and did not think obesity as a burden to the health system were found to be prejudicial. In our study, obesity prejudice scale scores did not differ according to the participants having a relative with obesity.

Levels of prejudice differed according to participants' sociodemographic characteristics. Individuals who were male, older, and had family members and friends with obesity were found to have lower hidden anti-obese prejudice. Tsai et al. observed that overweight male participants and those with obesity had a positive attitude toward their body weight compared with female participants ${ }^{15}$. In our study, female HCWs were found to have more prejudice than males. The study participants who were married and worked more than 20 years were also more prejudicial than single ones and those who worked less than 20 years. Obesity prejudice levels increased with the duration of work, possibly the result of challenges after many years with the complexity and difficulty of obesity management. Our study revealed that most HCWs had high prejudice scores, although they stated their preference to provide health care to individuals with obesity, revealing a professional dilemma for HCWs.

Although it was not significant, among the physicians who participated in our study, primary care physicians did not have higher prejudicial scores than those working at secondary or tertiary hospitals. Many of the studies in the literature were performed with primary care physicians, and there are limited studies comparing weight bias levels of physicians from different workplaces. Bocquier et al. reported that $30 \%$ of primary care physicians showed negative attitudes toward individuals with obesity ${ }^{16}$. Akman et al. also reported anti-obesity attitudes among primary care workers, including 
physicians and nurses, but the study sample was smaller than ours and did not include the attitudes of HCWs working in areas other than primary care ${ }^{7}$. As a specialty, the integrative approach of family medicine is very crucial in complex diseases like obesity. Furthermore, primary care HCWs are very important for counseling and access to health care services. Although similar prejudice levels of primary care physicians are promising in this study, prejudicial attitudes of HCWs, including physicians from any kind of medical workplace, should be considered because all have different roles in the management of obesity.

This study has several limitations. First, the data were collected from individuals through Internet and social media groups. We do not know how the individuals who did not accept to participate in this study differ from these study participants. Second, in this study, we evaluated participants' attitudes, opinions, and perceptions only via their declarations, and we might not have received information about their actual practices.

\section{CONCLUSIONS}

- The present study was carried out with the largest sample of HCWs in Turkey and contributes to valuable data on prejudice levels among HCWs.

- One-fourth of participants were found to be prejudicial, and half had a prejudicial tendency.
- Prejudice levels did not significantly differ according to the HCWs' specialty, workplace, or BMI.

- Etiology is multifactorial and individuals with obesity deserve a better attitude from HCWs.

Since weight bias affects the quality of health care provided to individuals with obesity, it is necessary to intervene and develop strategies to reduce or prevent prejudice among HCWs. In light of our findings, HCWs with significant roles in managing obesity should undergo postgraduation education programs that should:

1) Use updated information about the multifactorial etiology of obesity;

2) Raise awareness about the effect of weight bias and stigmatization on doctor-patient relationships; and

3) Have realistic targets in the management of obesity and emphasize the concept of multidisciplinary approaches.

\section{AUTHORS' CONTRIBUTIONS}

HP: Conceptualization, Supervision, Writing - original draft, Writing - review \& editing. OUT: Supervision, Writing original draft, Writing - review \& editing. MKS: Data curation, Supervision, Writing - original draft, Writing - review \& editing. MD: Supervision, Writing - review \& editing. HY: Supervision, Writing - review \& editing.

\section{REFERENCES}

1. Chu DT, Nguyet NTM, Nga VT, Lien NVY, Vo DD, Lien N, et al. An update on obesity: mental consequences and psychological interventions. Diabetes Metab Syndr. 2019;13(1):155-60. https://doi.org/10.1016/j.dsx.2018.07.015

2. Náfrádi L, Nakamoto K, Schulz PJ. Is patient empowerment the key to promote adherence? A systematic review of the relationship between self-efficacy, health locus of control and medication adherence. PLoS One. 2017;12(10):e0186458. https://doi.org/10.1371/journal.pone.0186458

3. Rand $K$, Vallis $M$, Aston $M$, Price $S$, Piccinini-Vallis $H$, Rehman $L$, et al. "It is not the diet; it is the mental part we need help with." A multilevel analysis of psychological, emotional, and social well-being in obesity. Int J Qual Stud Health Well-being. 2017;12(1):1306421. https://doi.org/10.1080/17482631.2017.1306421

4. Puhl RM, Latner JD, O'Brien K, Luedicke J, Danielsdottir S, Forhan M. A multinational examination of weight bias: predictors of anti-fat attitudes across four countries. Int J Obes (Lond). 2015;39(7):1166-73. https://doi.org/10.1038/ ijo.2015.32

5. Rubino F, Puhl RM, Cummings DE, Eckel RH, Ryan DH, Mechanick Jl, et al. Joint international consensus statement for ending stigma of obesity. Nat Med. 2020;26(4):485-97. https://doi.org/10.1038/s41591-020-0803-x
6. Alberga AS, Edache IY, Forhan M, Russell-Mayhew S. Weight bias and health care utilization: a scoping review. Prim Health Care Res Dev. 2019;20:e116. https://doi.org/10.1017/ S1463423619000227

7. Akman M, Kıvrakoğlu E, Cifcili S, Unalan PC. Weight bias among primary care health professionals: personal attitude matters. Obe Metab. 2010 [cited on Jun-Sep, 2010];14(23):63-8. Available from: https://www.researchgate.net/ publication/232612694_Weight_Bias_among_Primary_Care_ Health_Professionals_Personal_Attitude_Matters

8. Ercan A, Ok MA, Kızıltan G, Altun S. Development of obesity prejudice scale for students of health sciences: GAMS 27-obesity prejudice scale. DBHAD. 2015;3(2):29-43. https:// doi.org/10.17362/DBHAD.2015310322

9. Carr D, Friedman MA. Body weight and the quality of interpersonal relationships. Soc Psychol Q. 2006 [cited on Jun, 2006];69(2):127-49. Available from: http://www.jstor. org/stable/20141735

10. Cox ME, Yancy Junior WS, Coffman CJ, Ostbye T, Tulsky JA, Alexander SC, et al. Effects of counseling techniques on patients' weight-related attitudes and behaviors in a primary care clinic. Patient Educ Couns. 2011;85(3):363-8. https://doi. org/10.1016/j.pec.2011.01.024 
11. Yildiz M, Baysal HY. Prejudice against obesity in university students studying in health-related departments. Perspect Psychiatr Care. 2019;55(2):170-4. https://doi.org/10.1111/ ppc. 12314

12. Pearl RL, Puhl RM. Measuring internalized weight attitudes across body weight categories: validation of the modified weight bias internalization scale. Body Image. 2014;11(1):8992. https://doi.org/10.1016/j.bodyim.2013.09.005

13. Nair SC, Sheikh SM, Ibrahim H. Higher physician body mass index is associated with increased weight bias in an Arab country with high prevalence of obesity. Int J Prev Med. 2019;10:93. https://doi.org/10.4103/ijpvm.IJPVM_64_18
14. Latner JD, Durso LE, Mond JM. Health and health-related quality of life among treatment-seeking overweight and obese adults: associations with internalized weight bias. J Eat Disord. 2013;1:3. https://doi.org/10.1186/2050-2974-1-3

15. Tsai SA, Lv N, Xiao L, Ma J. Gender differences in weight-related attitudes and behaviors among overweight and obese adults in the United States. Am J Mens Health. 2016;10(5):389-98. https://doi.org/10.1177/1557988314567223

16. Bocquier A, Verger P, Basdevant A, Andreotti G, Baretge J, Villani P, et al. Overweight and obesity: knowledge, attitudes, and practices of general practitioners in france. Obes Res. 2005;13(4):787-95. https://doi.org/10.1038/oby.2005.89 